\title{
Genome-wide Association Study for Tumour Stage, Grade, Size, and Age at Diagnosis of Non-muscle- invasive Bladder Cancer
}

Citation for published version (APA):

Lipunova, N., Wesselius, A., Cheng, K. K., van Schooten, F. J., Bryan, R. T., Cazier, J-B., Galesloot, T. E., Kiemeney, L. A. L. M., \& Zeegers, M. P. (2019). Genome-wide Association Study for Tumour Stage, Grade, Size, and Age at Diagnosis of Non-muscle-invasive Bladder Cancer. European Urology Oncology, 2(4), 381-389. https://doi.org/10.1016/j.euo.2018.08.020

Document status and date:

Published: 01/07/2019

DOI:

10.1016/j.euo.2018.08.020

Document Version:

Publisher's PDF, also known as Version of record

\section{Document license:}

Taverne

Please check the document version of this publication:

- A submitted manuscript is the version of the article upon submission and before peer-review. There can be important differences between the submitted version and the official published version of record.

People interested in the research are advised to contact the author for the final version of the publication, or visit the DOI to the publisher's website.

- The final author version and the galley proof are versions of the publication after peer review.

- The final published version features the final layout of the paper including the volume, issue and page numbers.

Link to publication

\footnotetext{
General rights rights.

- You may freely distribute the URL identifying the publication in the public portal. please follow below link for the End User Agreement:

www.umlib.nl/taverne-license

Take down policy

If you believe that this document breaches copyright please contact us at:

repository@maastrichtuniversity.nl

providing details and we will investigate your claim.
}

Copyright and moral rights for the publications made accessible in the public portal are retained by the authors and/or other copyright owners and it is a condition of accessing publications that users recognise and abide by the legal requirements associated with these

- Users may download and print one copy of any publication from the public portal for the purpose of private study or research.

- You may not further distribute the material or use it for any profit-making activity or commercial gain

If the publication is distributed under the terms of Article 25fa of the Dutch Copyright Act, indicated by the "Taverne" license above, 


\title{
Genome-wide Association Study for Tumour Stage, Grade, Size, and Age at Diagnosis of Non-muscle-invasive Bladder Cancer
}

\author{
Nadezda Lipunova ${ }^{a, b, c, *}$, Anke Wesselius ${ }^{b}$, Kar K. Cheng $^{d}$, Frederik-Jan van Schooten $^{e}$, \\ Richard T. Bryan ${ }^{a}$, Jean-Baptiste Cazier ${ }^{a, c}$, Tessel E. Galesloot ${ }^{f}$, Lambertus A.L.M. Kiemeney $^{f}$, \\ Maurice P. Zeegers ${ }^{a, b}$ \\ ${ }^{a}$ Institute of Cancer and Genomic Sciences, University of Birmingham, Birmingham, UK; ${ }^{\mathrm{b}}$ Department of Complex Genetics, Maastricht University, \\ The Netherlands; ' Centre for Computational Biology, University of Birmingham, UK; ${ }^{\mathrm{d}}$ Institute for Applied Health Research, University of Birmingham, UK; \\ ${ }^{\mathrm{e}}$ Department of Pharmacology and Toxicology, Maastricht University, The Netherlands; ${ }^{\mathrm{f}}$ Radboud University Medical Center, Radboud Institute for Health \\ Sciences, The Netherlands
}

\section{Article info}

Article history:

Accepted August 23, 2018

Associate Editor:

Alberto Briganti

Keywords:

Age

Grade

Genome-wide association study

Non-muscle-invasive bladder

cancer

Size

Stage

\begin{abstract}
Background: Non-muscle-invasive bladder cancer (NMIBC) causes a considerable health burden due to the high recurrence and progression rates. Past studies have identified multiple candidate loci associated with NMIBC prognosis, albeit lacking validation. Moreover, scarce reports exist on genetic susceptibility to independent prognostic predictors of NMIBC, such as stage or grade.

Objective: To investigate genetic associations with NMIBC tumour and patient characteristics at the time of diagnosis.

Design, setting, and participants: A sample of 653 NMIBC cases comes from the Bladder Cancer Prognosis Programme. Replication of the significant findings was conducted in the Nijmegen Bladder Cancer Study cohort $(N=1470)$.

Outcome measurements and statistical analysis: A genome-wide association study (GWAS) was carried out for outcomes of tumour size (as a continuous variable in centimetres), stage (Tis and T1 vs Ta), grade (G3 vs G2 and G1), and age (as continuous [years] and dichotomous [70.2 yr as a cut-off] variables).

Results and limitations: Significant $(p<5 \mathrm{E}-08)$ associations $(N=61)$ with tumour size, stage, grade, and age were identified in the GWAS discovery stage. None of the variants were independently significantly associated in the replication cohort. A meta-analysis of both cohorts suggests that rs180940944 (13q13.3 locus, NBEA) was associated with tumour size as a continuous variable ( $\beta=0.9 \mathrm{~cm}, p=2.92 \mathrm{E}-09$ ). However, other single nucleotide polymorphisms in this region did not show evidence of association in the meta-analysis.

Conclusions: Our study suggests that rs180940944 (NBEA) is associated with an increased NMIBC tumour size at the time of diagnosis. Given study limitations, further replication is essential to validate the finding.

Patient summary: The current study reports on a genome-wide association study on non-muscle-invasive bladder cancer tumour and patient characteristics. We suggest that NBEA gene might be associated with increased tumour size at the time of diagnosis. The result must be replicated to establish validity.
\end{abstract}

\footnotetext{
* Corresponding author. Institute of Cancer and Genomic Sciences, University of Birmingham, Birmingham B15 2TT, UK. Tel.: +447729189097.
}

E-mail addresses: nx1689@student.bham.ac.uk, n.lipunova@maastrichtuniversity.nl (N. Lipunova).

https://doi.org/10.1016/j.euo.2018.08.020

2588-9311/@ 2018 European Association of Urology. Published by Elsevier B.V. All rights reserved. 


\section{Introduction}

Urinary bladder cancer (UBC) accounts for 430000 new cases worldwide annually, with $70-80 \%$ of new cases presenting as non-muscle-invasive bladder cancer (NMIBC) [1]. NMIBC causes a significant burden on healthcare systems due to high recurrence and progression rates (5yr recurrence rate: $50-70 \%, 5-y r$ progression rate: $10-30 \%$ ) [1]. Considerable clinical improvements could be made by better, even personalised, prognostication and risk stratification [1]. There have been several attempts to apply different approaches for accurate disease prognostication, and although descriptive on a population level, a substantial lack of precision of individual outcomes remains [2], requiring ongoing improvement.

Few candidate-gene studies of UBC prognosis exist, with limited successful replication [3-5]. A recent study reported that out of 114 reported loci for UBC progression and prognosis, only six single nucleotide polymorphisms (SNPs) showed significant associations in an independent cohort, namely, NMIBC progression (rs6678136 [RGS4], rs11585883 [RGS5]), recurrence among bacillus CalmetteGuérin (BCG)-treated NMIBC patients (rs1799793 [ERCC2], rs187238 [IL18]), and muscle-invasive bladder cancer (MIBC) overall survival (rs12035879 [RGS5], rs2075786 [TERT]) [3]. Powerful genome-wide association studies (GWASs) on NMIBC prognosis show promise, but are still ongoing [6].

A previous attempt to include genetic variation failed to increase prognostic tool performance [7], suggesting that the issue is more complex. However, a later study utilised a relatively small panel of SNPs (170 000), which has lower power of discovering significant loci in comparison with genotype-imputed sets harbouring millions of variants for analysis [8]. The interstudy lack of consensus might be due to several reasons: spurious findings, lack of statistical power, and variation in outcome definition.

Other studies also suggest that significant genetic signals might be present only for tumours of certain grade or stage $[9,10]$. However, reports on genetic associations for characteristics that directly influence NMIBC outcome are scarce, precluding further investigations on their relevance for NMIBC prognostication.

To provide more evidence on potential genetic associations, we have performed a GWAS on key NMIBC characteristics (stage, grade, size of the tumour, European Organisation for Research and Treatment of Cancer [EORTC] risk category), as well as age at the time of diagnosis within the West Midlands' Bladder Cancer Prognosis Programme (BCPP) cohort including replication in the Nijmegen Bladder Cancer Study (NBCS).

\section{Patients and methods}

\subsection{Participants and genotyping}

BCPP is a prospective cohort that initially recruited 1544 eligible patients and is described in more detail elsewhere [11]. Clinical data on stage, grade, and size of tumours, and demographic information (age and gender) were gathered with bespoke case report forms. Tumour size of the largest tumour was established visually while performing cystoscopy. Blood samples of 888 participants with confirmed UBC were genotyped on the Illumina Infinium OmniExpress-24 BeadChip array (deCODE Genetics, Reykjavik, Iceland).

Tumours of stages pTa, pT1, or pTis were included to limit our analyses to NMIBC, resulting in a dataset of 712 cases.

\subsection{Quality control}

Quality control $(\mathrm{QC})$ procedures were carried out using PLINK v1.90 [12]. The exact thresholds applied and the number of exclusions per step are outlined in Figure 1.

Generic QC procedures per individual excluded those with an inconclusive gender call, excessive genotype missingness rate, increased or reduced genotype heterozygosity rate, duplicate samples, and related individuals.

To avoid any bias introduced by population stratification, a principal component analysis (PCA) was carried out. Investigation of PCA plots resulted in exclusion of clear population outliers. Genomic inflation factor $(\lambda)$ value was estimated for all outcomes of interest; none of the values exceeded 1.03 .

Marker-specific QC procedures excluded SNPs deviating from the Hardy-Weinberg equilibrium, those exceeding acceptable missing rate, and rare variants.

In total, a dataset consisting of 653 individuals and 597764 markers remained for further analyses.

\subsection{Imputation}

Imputation utilised a two-step approach: haplotype phasing by Eagle v2.3.2 [13], followed by genotype imputation with IMPUTE2 [14], using 1000 Genomes Phase 3 [15] as a reference panel in the genome build 19 (GRCh37/hg19). Once imputed, the dataset was filtered for SNPs with info values (an imputation accuracy measure) of $>0.3$ and minor allele frequencies (MAFs) of $>1 \%$, resulting in a dataset containing 11914228 markers available for genetic association analyses.

\subsection{Statistical analysis}

Statistical analyses were performed using SNP test v2.5.2 [8] and R statistical package (v3.3.2) [16].

To establish the relation between germline variation and tested outcomes, linear regression was used for continuous variables and logistic regression for all binary endpoints. Age was tested as a continuous (years) and binary variable (mean was considered as a cut-off value for categorisation [resulting in strata of $<\geq 70 \mathrm{yr}$ ]). Tumour size $(\mathrm{cm})$ was tested as a continuous and categorical variable $(<1 \geq 3 \mathrm{~cm}$ [17]). Stage (Tis and T1 vs Ta) and grade (G3 vs G2 and G1) were treated as binary variables. In addition, low-, intermediate-, and high-risk EORTC categories were assigned to each NMIBC case, and were tested as a dichotomous variable of high- versus low- and intermediate-risk groups [17].

All analyses were adjusted for participant gender and first five genetic principal components, to increase estimate precision and adjust for any potential residual population stratification bias. An association was held significant for $p<5 \mathrm{E}-08$ and promising for $p<5 \mathrm{E}-06$.

Post-GWAS power calculations were carried out in web-based GAS Power Calculator [18].

Manhattan and quantile-quantile graphs were plotted for each tested outcome. For significant hits, regional association plots were constructed using a LocusZOOM tool [19], except for hits that have not yet been assigned an ID (rsID). 

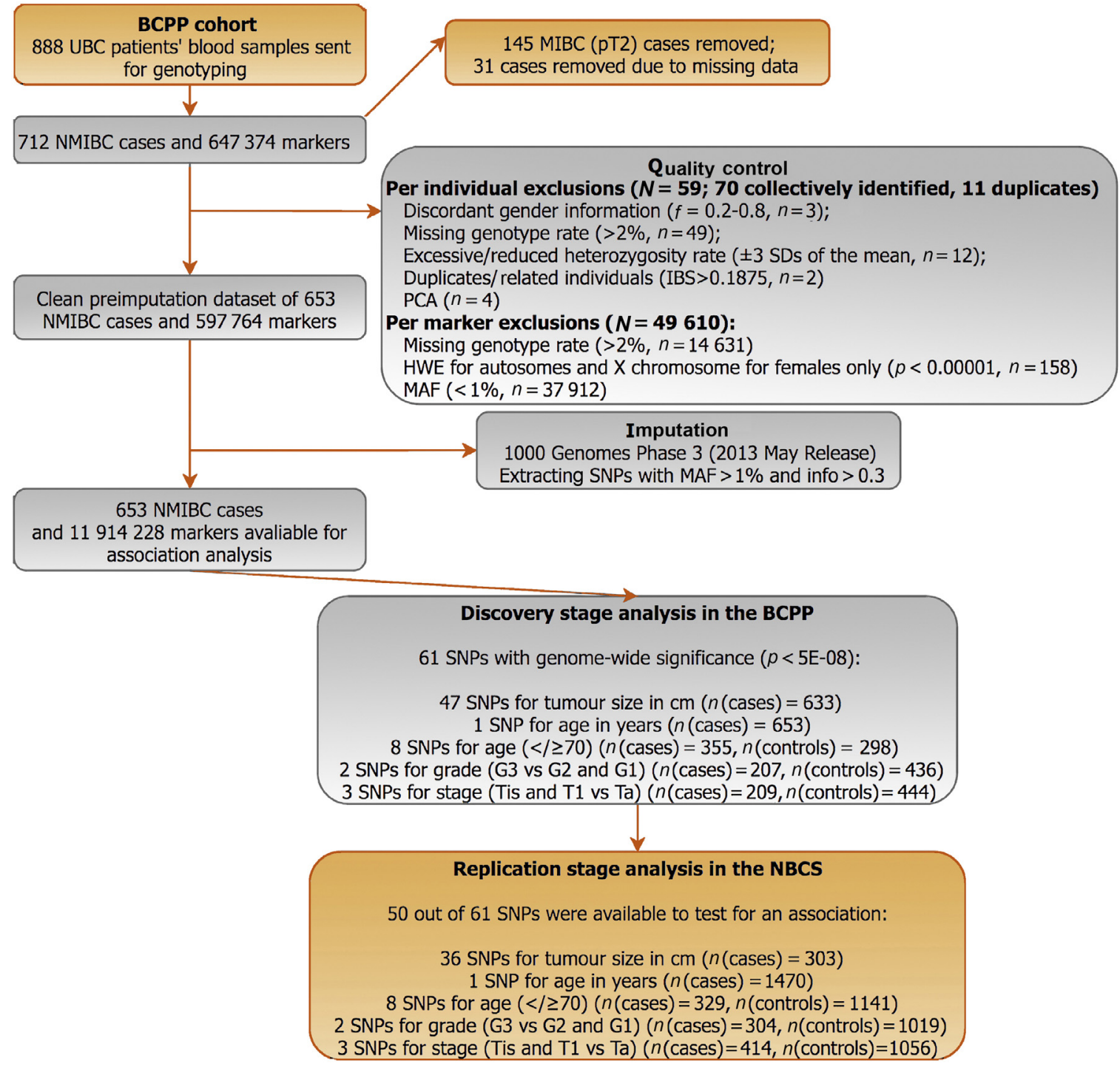

Fig. 1 - A flowchart of main steps in the GWAS analysis. BCPP = Bladder Cancer Prognosis Programme; HWE = Hardy-Weinberg equilibrium; MAF = minor allele frequency; $\mathrm{MIBC}=$ muscle-invasive bladder cancer; NBCS = Nijmegen Bladder Cancer Study; NMIBC = non-muscle-invasive bladder cancer; $\mathrm{PCA}=$ principal component analysis; $\mathrm{QC}=$ quality control; $\mathrm{SD}=$ standard deviation; $\mathrm{SNP}=$ single nucleotide polymorphism; $\mathrm{UBC}=$ urinary bladder cancer.

\subsection{Functional annotation}

Identified significant SNPs were mapped using a web-based SNPnexus tool [20], with Ensembl (version 74) [21] as a functional annotation system.

\subsection{Replication}

Genome-wide significant hits were attempted to replicate in a sample of 1470 NMIBC cases from the NBCS [22] (Fig. 1). Briefly, the NBCS recruited UBC patients via the population-based cancer registry in the Nijmegen region. Eligible cases were diagnosed during 1995-2006 and were under the age of $75 \mathrm{yr}$; additional data were collected via linkage with hospitalpatient records [22], including tumour size, which was reported after visual evaluation during cystoscopy. Details of genotype data cleaning and initial analysis are provided elsewhere [22].

We used META [23] software to perform meta-analysis on association results of both cohorts and calculated a combined $p$ value per SNP.
An inverse-variance method was used, assuming a random-effects model. $I^{2}$ index and $p$ value were calculated to evaluate potential heterogeneity between the estimates of the two cohorts [23].

\section{Results}

Baseline clinical characteristics of the discovery and replication cohorts are shown in Table 1.

The majority of cases in BCPP were male (78.1\%), with an average age of $70 \mathrm{yr}$. The mean tumour size was $2.5 \mathrm{~cm}$, and most of the participants were diagnosed with stage Ta (68\%) and T1 (30.5\%) tumours. More than a third of cases presented as G2 (37.5\%), followed by G3 (31.7\%) and G1 (29.2\%) NMIBC. The distribution of variable categories and measures was similar between the BCPP and NBCS cohorts.

In the discovery-stage analysis, a total of 61 SNPs, corresponding to 29 different regions, showed genome- 
Table 1 - Descriptive characteristics of the discovery (BCPP) and replication (NBCS) cohorts.

\begin{tabular}{|c|c|c|}
\hline Variables & Discovery set $(N=653)$ & Replication set $(N=1470)$ \\
\hline \multicolumn{3}{|l|}{ Age (yr) } \\
\hline Mean (SD) & $70.2(10.5)$ & $62.5(9.7)$ \\
\hline Median (range) & $71.5(34.3-91.5)$ & $64(25.0-91.0)$ \\
\hline \multicolumn{3}{|l|}{ Age (yr) } \\
\hline$<70(\%)$ & $298(45.6)$ & 329 (22.4) \\
\hline$\geq 70(\%)$ & $355(54.4)$ & $1141(77.6)$ \\
\hline \multicolumn{3}{|l|}{ Sex } \\
\hline Male (\%) & $510(78.1)$ & $1208(82.2)$ \\
\hline Female (\%) & $143(21.9)$ & $262(17.8)$ \\
\hline \multicolumn{3}{|l|}{ Tumour size $(\mathrm{cm})$} \\
\hline Mean (SD) & $2.5(1.9)$ & $2.4(1.3)$ \\
\hline Median (range) & $2.0(0.2-15.0)$ & $2.0(0.05-7.5)$ \\
\hline Missing (\%) & $20(3.1)$ & $1168(79.5)$ \\
\hline \multicolumn{3}{|l|}{ Stage } \\
\hline $\mathrm{Ta}(\%)$ & $444(68.0)$ & $1056(71.8)$ \\
\hline $\mathrm{T} 1(\%)$ & $199(30.5)$ & 349 (23.7) \\
\hline Tis $(\%)$ & $10(1.5)$ & $65(4.4)$ \\
\hline \multicolumn{3}{|l|}{ Grade } \\
\hline G1 (\%) & $191(29.2)$ & $401(27.3)$ \\
\hline G2 (\%) & $245(37.5)$ & $618(42.0)$ \\
\hline G3 (\%) & $207(31.7)$ & $304(20.7)$ \\
\hline Missing (\%) & $10(1.5)$ & $147(10.0)$ \\
\hline \multicolumn{3}{|l|}{ EORTC risk category } \\
\hline Low (\%) & $66(10.1)$ & NA \\
\hline Intermediate (\%) & $276(42.3)$ & NA \\
\hline High (\%) & $311(47.6)$ & NA \\
\hline \multicolumn{3}{|c|}{$\begin{array}{l}\text { BCPP = Bladder Cancer Prognosis Programme; EORTC = European } \\
\text { Organisation for Research and Treatment of Cancer; NA = not available; } \\
\text { NBCS = Nijmegen Bladder Cancer Study; SD = standard deviation. }\end{array}$} \\
\hline
\end{tabular}

wide statistically significant associations with at least one of the outcomes. Out of those, 20 loci were mapped to genes (all intronic regions; Table 2). Significant associations were observed for size and age as continuous variables, as well as for binary outcomes of stage, grade, and age.

Most of the SNPs $(N=47)$ were found to be associated with tumour size, the effect sizes ranging from 0.65 (rs35225990 in FAM194B, $p=2.85 \mathrm{E}-08)$ to 2.6 (rs370572716 in 9p13.1, $p=4.04 \mathrm{E}-09$ ) $\mathrm{cm}$ (Table 2).

One SNP in 9q22.32, rs142492877, showed a statistically significant association with decreased age at diagnosis of almost $1 \operatorname{yr}(ß=-0.95$, standard error $[\mathrm{SE}]=0.16, p=1.05 \mathrm{E}-08)$. Age as a binary trait showed associations in the same direction, although in a different genomic region (7q31.33) with an odds ratio (OR) ranging between 2.46 (rs17149580, $p=2.18 \mathrm{E}-08$ ) and 2.51 (rs17149636, $p=1.62 \mathrm{E}-08$ ) across eight SNPs.

The 14q11.2 locus showed strong associations with being diagnosed with a higher grade of NMIBC (rs15091489 in the TRAV16 gene $[\mathrm{OR}=3.42,95 \%$ confidence interval $\{\mathrm{CI}\}$ : $2.11-$ 5.55, $p=5.13 \mathrm{E}-09]$ and $\mathrm{rs} 116923391[\mathrm{OR}=3.86,95 \% \mathrm{CI}$ : 2.38-6.26, $p=2.07 \mathrm{E}-10]$ ).

Several protective variants for tumour stage were observed, namely, rs117248430 in ANKS6 (OR = 0.003, 95\% $\mathrm{CI}=1.71 \mathrm{E}-09-3895.6, p=3.73 \mathrm{E}-08)$, and two markers in the SLC01B1 gene $(\mathrm{rs} 76497895[\mathrm{OR}=0.03,95 \% \mathrm{CI}=0.001-0.83$, $p=4.18 \mathrm{E}-08]$; rs $116946525[\mathrm{OR}=0.03,95 \% \mathrm{CI}=0.001-0.83$, $p=4.23 \mathrm{E}-08])$. The strength of the effect and corresponding confidence intervals in ANKS6 might be explained by a very low MAF $(<0.01 \%)$ among cases.
A Manhattan plot for tumour size as a continuous outcome (Fig. 2) also shows that there are several polymorphisms in linkage disequilibrium (LD) with the leading SNP (Manhattan plots for all other tested outcomes are available in the Supplementary Fig. 1-6).

Regional association plot of 13q13.3 (Fig. 3) in the BCPP confirms high LD with surrounding variants, all mapping to the NBEA gene (although they did not reach the statistical significance). Regional association plots for the remaining SNPs identified in the discovery stage are presented in Supplementary Figures 7-33.

In the replication stage, 50 out of 61 SNPs were available for test in NBCS (Table 2). None of these SNPs were significantly associated with the same outcomes in NBCS. A meta-analysis of both cohorts showed variant rs180940944 in $13 q 13.3$ locus to be associated with increased tumour size at diagnosis $(B=0.96, \mathrm{SE}=0.16, p=2.92 \mathrm{E}-09$ ), although the effect is likely driven by BCPP data. Nevertheless, a low $I^{2}$ estimate $\left(I^{2}=0 \%, p\right.$ [heterogeneity] $\left.=0.75\right)$ indicated that there was no significant heterogeneity between the two cohorts for the replicated SNP. A conditional association analysis on rs180940944 showed that the associations in the NBEA gene are likely to be driven by the top SNP, as none of the variants have reached genome-wide significance when controlled for the effect of rs180940944 (Supplementary Fig. 34). Nevertheless, the analysis also suggests that there is a region in the NBEA gene of mildly inflated $p$ values, independent of the rs180940944.

\section{Discussion}

We have investigated genetic associations with NMIBC tumour (size, stage, and grade) and patient (age and EORTC risk category) characteristics at the time of diagnosis within the BCPP cohort.

Multiple loci were identified in the discovery stage, which are novel in the context of NMIBC. One SNP, rs180940944, has reached statistical significance in a meta-analysis of two NMIBC cohorts, mapping to the intronic region of the NBEA gene on 13q13.3. However, associations of other SNPs in the NBEA have failed to be reproduced.

NBEA proteins have mostly been observed to play a significant role in synapse development and function [24]. NBEA dysregulation does not affect the establishment of synapses per se, but rather their intracellular organisation [24]. An in-depth analysis revealed that impaired synaptic ability was mostly due to the inappropriate distribution of actin, a protein essential for synapse cytoskeleton structure [24]. The effect is most likely present due to alterations in the Golgi-dependent processes of inter- and intracellular compound trafficking, including actin and neural receptors [24].

The synaptic alterations are likely to be the contributing cause of autism spectrum disorders [24]; however, the Golgi-related pathway may have a wider phenotypic manifestation [25], including cancer. The prognostic utility of NBEA has been investigated in gastric cancer [26] and 
Table 2 - Genetic associations with NMIBC tumour and patient characteristics at baseline in the discovery (BCPP) and replication (NBCS) stages and a joint analysis.

\begin{tabular}{|c|c|c|c|c|c|c|c|c|c|c|c|c|c|c|c|}
\hline \multirow[t]{2}{*}{ Phenotype } & \multirow[t]{2}{*}{ rsID } & \multirow[t]{2}{*}{ BP } & \multirow[t]{2}{*}{ Locus } & \multirow[t]{2}{*}{ REF } & \multirow[t]{2}{*}{ ALT } & \multicolumn{4}{|c|}{ Discovery cohort (BCPP) } & \multicolumn{4}{|c|}{ Replication cohort (NBCS) } & \multirow[t]{2}{*}{$p$ (joint) } & \multirow[t]{2}{*}{ Annotation } \\
\hline & & & & & & MAF & ß & OR $(95 \% \mathrm{CI})$ & $p$ value & MAF & ß & OR $(95 \% \mathrm{CI})$ & $p$ value & & \\
\hline Size $(\mathrm{cm})$ & rs180940944 & 35950093 & $13 q 13.3$ & c & $\mathbf{T}$ & 0.03 & $0.97(0.16)$ & & $6.73 \mathrm{E}-09$ & 0.004 & $0.71(0.80)$ & & 0.38 & 2.92E-09 & NBEA \\
\hline Size $(\mathrm{cm})$ & rs113705641 & 5375733 & 3p26.1 & A & G & 0.02 & $1.38(0.25)$ & & 2.99E-08 & 0.02 & $0.50(0.34)$ & & 0.14 & 0.03 & - \\
\hline Size $(\mathrm{cm})$ & rs74603364 & 79509518 & $6 q 14.1$ & C & $\mathrm{T}$ & 0.02 & $1.38(0.22)$ & & $6.54 \mathrm{E}-10$ & 0.02 & $0.50(0.31)$ & & 0.10 & 0.03 & - \\
\hline Size $(\mathrm{cm})$ & rs143076258 & 136382230 & $4 q 28.3$ & G & A & 0.02 & $1.18(0.20)$ & & $9.21 \mathrm{E}-09$ & 0.01 & $0.35(0.38)$ & & 0.36 & 0.04 & - \\
\hline Size $(\mathrm{cm})$ & rs4646911 & 34856662 & $6 \mathrm{p} 21.31$ & G & A & 0.01 & $1.67(0.30)$ & & $3.76 \mathrm{E}-08$ & 0.01 & $0.47(0.53)$ & & 0.37 & 0.05 & TAF11 \\
\hline Size $(\mathrm{cm})$ & rs180910528 & 79821806 & 6q14.1 & A & C & 0.01 & $1.74(0.28)$ & & $4.67 \mathrm{E}-10$ & 0.01 & $0.43(0.36)$ & & 0.23 & 0.09 & - \\
\hline Size $(\mathrm{cm})$ & rs 187040828 & 79802426 & 6q14.1 & $\mathrm{T}$ & C & 0.01 & $1.74(0.28)$ & & $4.89 \mathrm{E}-10$ & 0.02 & $0.36(0.34)$ & & 0.29 & 0.12 & - \\
\hline Size $(\mathrm{cm})$ & rs80026656 & 53756380 & $18 \mathrm{q} 21.2$ & A & G & 0.01 & $1.50(0.26)$ & & 1.27E-08 & 0.02 & $0.29(0.31)$ & & 0.34 & 0.13 & CTD-2008L17.2 \\
\hline Size $(\mathrm{cm})$ & rs35225990 & 46117489 & $13 q 14.13$ & C & $\mathrm{T}$ & 0.07 & $0.65(0.12)$ & & $2.85 \mathrm{E}-08$ & 0.06 & $0.11(0.17)$ & & 0.51 & 0.14 & FAM194B \\
\hline Size $(\mathrm{cm})$ & rs144383242 & 79489625 & 6q14.1 & G & $\mathrm{T}$ & 0.01 & $1.66(0.26)$ & & $1.88 \mathrm{E}-10$ & 0.01 & $0.30(0.34)$ & & 0.37 & 0.14 & - \\
\hline Size $(\mathrm{cm})$ & rs117587674 & 79432536 & 6q14.1 & G & A & 0.01 & $1.67(0.26)$ & & $1.70 \mathrm{E}-10$ & 0.01 & $0.30(0.34)$ & & 0.37 & 0.14 & - \\
\hline Size $(\mathrm{cm})$ & rs180991319 & 36850863 & 19q13.12 & $\mathrm{T}$ & A & 0.01 & $1.87(0.33)$ & & 2.35E-08 & 0.00 & $0.12(0.98)$ & & 0.90 & 0.14 & ZFP14 \\
\hline Size $(\mathrm{cm})$ & rs117407537 & 35652859 & $13 q 13.3$ & G & A & 0.03 & $0.98(0.17)$ & & 2.16E-08 & 0.02 & $0.15(0.30)$ & & 0.62 & 0.15 & NBEA \\
\hline Size $(\mathrm{cm})$ & rs77827766 & 35808410 & $13 q 13.3$ & G & C & 0.03 & $1.00(0.18)$ & & $1.58 \mathrm{E}-08$ & 0.02 & $0.15(0.30)$ & & 0.61 & 0.15 & NBEA \\
\hline Size $(\mathrm{cm})$ & rs117318492 & 35776449 & $13 q 13.3$ & $\mathrm{~T}$ & C & 0.03 & $1.00(0.18)$ & & $1.58 \mathrm{E}-08$ & 0.02 & $0.15(0.30)$ & & 0.61 & 0.15 & NBEA \\
\hline Size $(\mathrm{cm})$ & rs112579236 & 35742893 & $13 q 13.3$ & A & G & 0.03 & $0.96(0.17)$ & & 3.47E-08 & 0.02 & $0.14(0.29)$ & & 0.62 & 0.15 & NBEA \\
\hline Size $(\mathrm{cm})$ & rs117989790 & 35758974 & $13 q 13.3$ & G & C & 0.03 & $1.01(0.18)$ & & $1.47 \mathrm{E}-08$ & 0.02 & $0.15(0.30)$ & & 0.61 & 0.15 & SCAND3P1 \\
\hline Size $(\mathrm{cm})$ & rs117286929 & 35804780 & $13 q 13.3$ & A & G & 0.03 & $1.01(0.18)$ & & $1.52 \mathrm{E}-08$ & 0.02 & $0.15(0.30)$ & & 0.61 & 0.15 & NBEA \\
\hline Size $(\mathrm{cm})$ & rs200899670 & 46170799 & $15 q 21.1$ & TCAAA & $\mathrm{T}$ & 0.01 & $2.47(0.34)$ & & $1.63 \mathrm{E}-12$ & 0.03 & $0.42(0.29)$ & & 0.16 & 0.16 & RP11-718011.1 \\
\hline Size $(\mathrm{cm})$ & rs143664498 & 35919424 & $13 q 13.3$ & C & A & 0.03 & $0.99(0.17)$ & & $1.84 \mathrm{E}-08$ & 0.02 & $0.12(0.29)$ & & 0.69 & 0.18 & NBEA \\
\hline Size $(\mathrm{cm})$ & rs117382849 & 35924241 & $13 q 13.3$ & A & G & 0.03 & $0.99(0.17)$ & & $1.90 \mathrm{E}-08$ & 0.02 & $0.12(0.29)$ & & 0.69 & 0.18 & NBEA \\
\hline Size $(\mathrm{cm})$ & rs117576619 & 35887557 & $13 q 13.3$ & $\mathrm{~T}$ & C & 0.03 & $1.00(0.17)$ & & $1.66 \mathrm{E}-08$ & 0.02 & $0.12(0.29)$ & & 0.69 & 0.18 & NBEA \\
\hline Size $(\mathrm{cm})$ & rs144366722 & 35845426 & 13q13.3 & A & G & 0.03 & $1.00(0.18)$ & & $1.57 \mathrm{E}-08$ & 0.02 & $0.12(0.29)$ & & 0.69 & 0.18 & NBEA \\
\hline Size $(\mathrm{cm})$ & rs116854115 & 35865482 & $13 q 13.3$ & $\mathrm{~T}$ & C & 0.03 & $1.01(0.18)$ & & 1.57E-08 & 0.02 & $0.12(0.29)$ & & 0.69 & 0.18 & NBEA \\
\hline Size $(\mathrm{cm})$ & rs151184057 & 5665859 & $2 \mathrm{p} 25.2$ & C & $\mathrm{T}$ & 0.01 & $1.51(0.27)$ & & $3.88 \mathrm{E}-08$ & 0.02 & $0.19(0.35)$ & & 0.59 & 0.19 & - \\
\hline Size $(\mathrm{cm})$ & rs78813710 & 3160739 & $7 \mathrm{p} 22.2$ & $\mathrm{~T}$ & G & 0.01 & $1.57(0.28)$ & & $3.12 \mathrm{E}-08$ & 0.01 & $0.15(0.41)$ & & 0.72 & 0.21 & - \\
\hline Size $(\mathrm{cm})$ & rs117889651 & 35987813 & $13 q 13.3$ & A & G & 0.03 & $0.92(0.17)$ & & $3.91 \mathrm{E}-08$ & 0.03 & $0.06(0.26)$ & & 0.83 & 0.24 & NBEA \\
\hline Size $(\mathrm{cm})$ & rs148373773 & 14919905 & $6 \mathrm{p} 23$ & AC & A & 0.03 & $0.96(0.17)$ & & 3.17E-08 & 0.05 & $0.07(0.20)$ & & 0.72 & 0.24 & - \\
\hline Size $(\mathrm{cm})$ & rs75585701 & 2194093 & $3 p 26.3$ & C & G & 0.02 & $1.60(0.22)$ & & $2.66 \mathrm{E}-12$ & 0.02 & $0.09(0.33)$ & & 0.79 & 0.25 & CNTN4 \\
\hline Grade (G3 vs G2 and G1) & rs150914897 & 22460455 & $14 q 11.2$ & C & $\mathrm{T}$ & 0.06 & & $3.42(2.11-5.55)$ & $5.13 \mathrm{E}-09$ & 0.05 & & $1.11(0.74-1.65)$ & 0.60 & 0.26 & TRAV16 \\
\hline Size $(\mathrm{cm})$ & rs75801131 & 70017072 & $18 \mathrm{q} 22.3$ & c & A & 0.02 & $1.53(0.25)$ & & $2.08 \mathrm{E}-09$ & 0.02 & $0.04(0.32)$ & & 0.90 & 0.28 & - \\
\hline Age (yr) & rs142492877 & 98482828 & $9 q 22.32$ & A & G & 0.04 & $-0.95(0.16)$ & & $1.05 \mathrm{E}-08$ & 0.03 & $-0.03(0.12)$ & & 0.79 & 0.29 & - \\
\hline Size $(\mathrm{cm})$ & rs76779534 & 11737232 & 10p14 & A & G & 0.02 & $1.30(0.22)$ & & $5.57 \mathrm{E}-09$ & 0.01 & $-0.09(0.50)$ & & 0.86 & 0.33 & - \\
\hline Size $(\mathrm{cm})$ & rs73570873 & 11737713 & 10p14 & $\mathrm{T}$ & A & 0.02 & $1.30(0.22)$ & & 4.97E-09 & 0.01 & $-0.10(0.50)$ & & 0.84 & 0.34 & - \\
\hline Size $(\mathrm{cm})$ & rs12265817 & 11738801 & 10p14 & C & $\mathrm{T}$ & 0.02 & $1.28(0.22)$ & & $6.82 \mathrm{E}-09$ & 0.01 & $-0.13(0.50)$ & & 0.79 & 0.36 & - \\
\hline Grade (G3 vs G2 and G1) & rs116923391 & 22406144 & $14 q 11.2$ & c & $\mathrm{T}$ & 0.06 & & $3.86(2.38-6.26)$ & $2.07 \mathrm{E}-10$ & 0.06 & & $0.93(0.64-1.37)$ & 0.69 & 0.37 & - \\
\hline Age $(<1 \geq 70$ yr $)$ & rs41515546 & 125998959 & 7q31.33 & $\mathrm{T}$ & C & 0.16 & & $2.49(1.81-3.44)$ & $1.96 \mathrm{E}-08$ & 0.15 & & $0.93(0.72-1.19)$ & 0.59 & 0.40 & - \\
\hline Age $(<\mid \geq 70 \mathrm{yr})$ & rs17149636 & 126018952 & $7 q 31.33$ & A & G & 0.17 & & $2.51(1.82-3.46)$ & $1.62 \mathrm{E}-08$ & 0.15 & & $0.92(0.72-1.18)$ & 0.57 & 0.40 & AC000370.2 \\
\hline Age $(<\mid \geq 70 \mathrm{yr})$ & rs17149628 & 126006965 & $7 q 31.33$ & C & $\mathrm{T}$ & 0.16 & & $2.49(1.81-3.44)$ & $1.95 \mathrm{E}-08$ & 0.15 & & $0.92(0.72-1.18)$ & 0.56 & 0.41 & - \\
\hline Age $(<\mid \geq 70 \mathrm{yr})$ & rs12666814 & 125979540 & $7 q 31.33$ & C & $\mathrm{T}$ & 0.16 & & $2.49(1.80-3.44)$ & $2.05 \mathrm{E}-08$ & 0.15 & & $0.92(0.72-1.18)$ & 0.55 & 0.41 & - \\
\hline Age $(<\mid \geq 70 \mathrm{yr})$ & rs73223045 & 125992106 & $7 q 31.33$ & G & C & 0.16 & & $2.49(1.81-3.44)$ & $1.97 \mathrm{E}-08$ & 0.15 & & $0.92(0.72-1.18)$ & 0.53 & 0.41 & - \\
\hline Age $(<\mid \geq 70 \mathrm{yr})$ & rs12673089 & 126006133 & $7 q 31.33$ & C & $\mathrm{T}$ & 0.16 & & $2.49(1.81-3.44)$ & $1.95 \mathrm{E}-08$ & 0.15 & & $0.92(0.72-1.18)$ & 0.53 & 0.41 & - \\
\hline Age $(<1 \geq 70 \mathrm{yr})$ & rs17149580 & 125978216 & $7 q 31.33$ & A & G & 0.16 & & $2.46(1.78-3.39)$ & $2.18 \mathrm{E}-08$ & 0.15 & & $0.91(0.71-1.17)$ & 0.50 & 0.42 & - \\
\hline Age $(<1 \geq 70 \mathrm{yr})$ & rs17149630 & 126006996 & $7 q 31.33$ & c & $\mathrm{T}$ & 0.16 & & $2.49(1.81-3.44)$ & $1.95 \mathrm{E}-08$ & 0.15 & & $0.91(0.71-1.17)$ & 0.49 & 0.42 & - \\
\hline
\end{tabular}


Table 2 (Continued)

\begin{tabular}{|c|c|c|c|c|c|c|c|c|c|c|c|c|c|c|c|}
\hline \multirow[t]{2}{*}{ Phenotype } & \multirow[t]{2}{*}{ rsID } & \multirow[t]{2}{*}{ ВР } & \multirow[t]{2}{*}{ Locus } & \multirow[t]{2}{*}{ REF } & \multirow[t]{2}{*}{ ALT } & \multicolumn{4}{|c|}{ Discovery cohort (BCPP) } & \multicolumn{4}{|c|}{ Replication cohort (NBCS) } & \multirow[t]{2}{*}{$p$ (joint) } & \multirow[t]{2}{*}{ Annotation } \\
\hline & & & & & & MAF & $\beta$ & OR $(95 \% \mathrm{CI})$ & $p$ value & MAF & $\beta$ & OR $(95 \% \mathrm{CI})$ & $p$ value & & \\
\hline Stage (Tis and T1 vs Ta) & rs76497895 & 21393419 & $12 \mathrm{p} 12.1$ & G & $T$ & 0.02 & & $0.03(0.001-0.83)$ & $4.18 \mathrm{E}-08$ & 0.02 & & $1.39(0.84-2.32)$ & 0.10 & 0.44 & SLCO1B1 \\
\hline Stage (Tis and $\mathrm{T} 1 \mathrm{vs} \mathrm{Ta}$ ) & rs116946525 & 21391500 & $12 \mathrm{p} 12.1$ & $\mathrm{~T}$ & A & 0.02 & & $0.03(0.001-0.83)$ & $4.23 \mathrm{E}-08$ & 0.02 & & $1.39(0.84-2.32)$ & 0.10 & 0.44 & SLC01B1 \\
\hline Size $(\mathrm{cm})$ & rs141965746 & 46544198 & $21 \mathrm{q} 22.3$ & $\mathrm{~T}$ & G & 0.02 & $1.27(0.23)$ & & $3.61 \mathrm{E}-08$ & 0.02 & $-0.21(0.28)$ & & 0.45 & 0.47 & ADARB1 \\
\hline Stage (Tis and $\mathrm{T} 1 \mathrm{vs} \mathrm{Ta}$ ) & rs117248430 & 101506559 & $9 q 22.33$ & $\mathrm{C}$ & $\mathrm{T}$ & 0.01 & & $0.003(1.71 \mathrm{E}-09-3895.6)$ & $3.73 \mathrm{E}-08$ & 0.01 & & $1.13(0.50-2.56)$ & 0.76 & 0.48 & ANKS6 \\
\hline Size $(\mathrm{cm})$ & rs188958632 & 38266174 & $14 q 21.1$ & G & A & 0.01 & $1.53(0.27)$ & & $1.42 \mathrm{E}-08$ & 0.03 & $-0.39(0.22)$ & & 0.08 & 0.56 & TTC6 \\
\hline Size $(\mathrm{cm})$ & rs189352109 & 145555946 & $2 q 22.3$ & $\mathrm{~T}$ & C & 0.01 & $1.46(0.26)$ & & $3.77 \mathrm{E}-08$ & 0.01 & $-0.75(0.45)$ & & 0.10 & 0.73 & TEX41 \\
\hline Size $(\mathrm{cm})$ & rs3752175 & 2516839 & 19p13.3 & G & A & 0.01 & $2.14(0.38)$ & & 3.57E-08 & NA & NA & NA & NA & NA & GNG7 \\
\hline Size $(\mathrm{cm})$ & rs182792180 & 3164492 & $7 \mathrm{p} 22.2$ & C & $\mathrm{T}$ & 0.01 & $1.59(0.28)$ & & $2.18 \mathrm{E}-08$ & NA & NA & NA & NA & NA & - \\
\hline Size $(\mathrm{cm})$ & rs117108730 & 35735418 & $13 q 13.3$ & $\mathrm{~T}$ & C & 0.02 & $1.10(0.19)$ & & $5.83 \mathrm{E}-09$ & NA & NA & NA & NA & NA & NBEA \\
\hline Size $(\mathrm{cm})$ & rs117215187 & 35950090 & $13 q 13.3$ & C & $\mathrm{T}$ & 0.03 & $0.97(0.16)$ & & $6.73 \mathrm{E}-09$ & NA & NA & NA & NA & NA & NBEA \\
\hline Size $(\mathrm{cm})$ & 14 & 38247577 & 14q21.1 & CTGG & C & 0.01 & $2.21(0.37)$ & & $2.46 \mathrm{E}-09$ & NA & NA & NA & NA & NA & TTC6 \\
\hline Size $(\mathrm{cm})$ & rs 183885923 & 38310637 & 19q13.13 & G & A & 0.01 & $1.96(0.33)$ & & $5.64 \mathrm{E}-09$ & NA & NA & NA & NA & NA & CTD-2554C21.2 \\
\hline Size $(\mathrm{cm})$ & rs370572716 & 38920614 & 9p13.1 & $\mathrm{T}$ & A & 0.01 & $2.59(0.43)$ & & $4.04 \mathrm{E}-09$ & NA & NA & NA & NA & NA & - \\
\hline Size $(\mathrm{cm})$ & rs 2937268 & 66553607 & $1 \mathrm{p} 31.3$ & C & $\mathrm{T}$ & 0.04 & $0.94(0.16)$ & & $1.07 \mathrm{E}-08$ & NA & NA & NA & NA & NA & PDE4B \\
\hline Size $(\mathrm{cm})$ & $\mathrm{X}$ & 117703032 & $23 q 24$ & C & $\mathrm{T}$ & 0.01 & $1.05(0.18)$ & & 7.93E-09 & NA & NA & NA & NA & NA & DOCK11 \\
\hline Size $(\mathrm{cm})$ & rs76670367 & 136254151 & $4 q 28.3$ & G & $\mathrm{T}$ & 0.02 & $1.16(0.21)$ & & $2.97 \mathrm{E}-08$ & NA & NA & NA & NA & NA & - \\
\hline Size $(\mathrm{cm})$ & rs151220146 & 180402493 & $2 \mathrm{q} 31.2$ & $\mathrm{CA}$ & C & 0.01 & $2.03(0.31)$ & & $8.03 \mathrm{E}-11$ & NA & NA & NA & NA & NA & ZNF385B \\
\hline
\end{tabular}



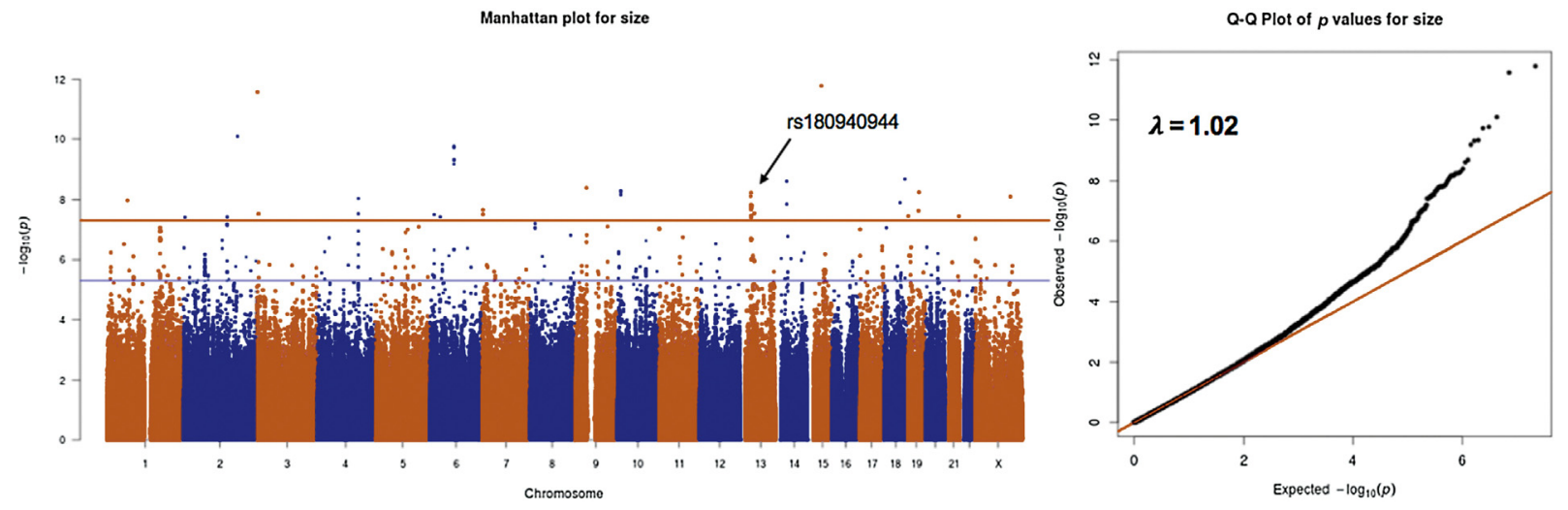

Fig. 2 - Manhattan and quantile-quantile plots for tumour size $(\mathrm{cm})$ in the BCPP cohort. Blue and red horizontal lines indicate $p$ values of $<5 E-06$ and $<5 E-08$, respectively. Highlighted variant shows the SNP reaching statistical significance in the meta-analysis of BCPP and NBCS (independent association was observed in the BCPP, and no significant effect was detected among NBCS participants only). BCPP = Bladder Cancer Prognosis Programme; NBCS = Nijmegen Bladder Cancer Study; $Q-Q=$ quantile-quantile; SNP = single nucleotide polymorphism.

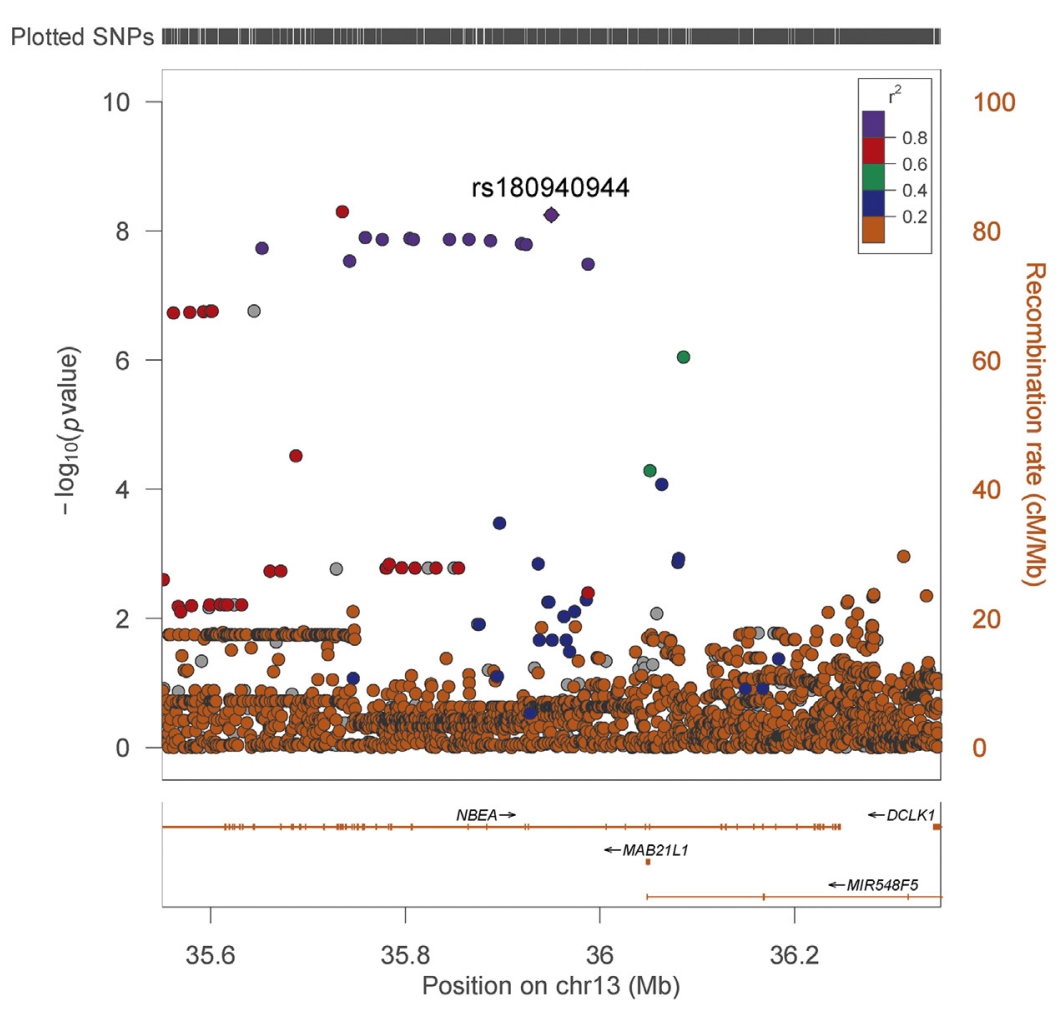

Fig. 3 - Regional association plot for 13q13.3 locus with tumour size (cm) in NMIBC patients of the BCPP cohort (annotated SNP has reached statistical significance in the meta-analysis of BCPP and NBCS cohorts). BCPP = Bladder Cancer Prognosis Programme; NBCS = Nijmegen Bladder Cancer Study; SNP = single nucleotide polymorphism.

oropharyngeal squamous cell carcinomas [27], with promising results. Collectively, these observations implicate the pleiotropic nature of NBEA effect across a variety of traits.

In our study, we suggest that there is an association between NBEA and increased NMIBC tumour size. The role of Golgi complex in cancer progression has been reported independently, and disruptions in normal protein transportation can contribute to increased tumour size and, eventually, progression [25].
Our findings should be interpreted cautiously. Substantial sample sizes of specific phenotypes such as ours are rare and suffer from limited power to capture true genetic associations, and spurious associations due to random effects cannot be ruled out. Our post hoc power calculations [18] underscore the importance of current analysis being run on bigger cohorts (eg, association rs150914897 [14q11.2] of an OR $=3.42$ had power of $79 \%$, but it drops to only $16 \%$ for an $\mathrm{OR}=2.5$; hence, we may have missed existing associations of more modest effect size). 
Furthermore, tumour size measurements are subject to variability, the degree of which is difficult to establish. The lack of any genome-wide significant associations for categorised tumour size $(</ \geq 3 \mathrm{~cm}$ [17]) adds substantial caution in consideration of our main findings and study power. However, clinically relevant tumour size categories may not be adequate in a genetic context, and different categorisation may be used in future analyses.

Our study focused only on NMIBC instead of a merged group of UBC, and we are unable to comment on whether these genetic loci are relevant for advanced UBC. Given considered limitations, we see this study as true to the GWAS design of hypothesis-generating nature, instead of one offering conclusive findings. Hence, further replication is of essence to establish validity of described results.

The 13q13.3 locus has not been observed in prior studies on NMIBC. It might be due to the use of an independent prognostic marker of NMIBC (ie, tumour size) in our study instead of recurrence and/or progression as an outcome. A larger tumour indicates a worse disease course [17], but there are other components that contribute to NMIBC prognosis. In a clinical setting, each tumour characteristic (eg, size) carries a different weighting [17], collectively contributing to an endpoint (eg, recurrence).

Importantly, powerful studies on UBC risk have already shown some signals to be associated only with MIBC (UBC of T2-T4) [10]. Furthermore, a genome-wide methylation investigation on high-grade NMIBC cases revealed epigenetic changes different from their low-grade counterparts [9]. Direct comparability of these reports is limited, but we see the unravelling genetic complexity within UBC as a connecting thread between all studies. We therefore believe that separate genetic relationships are likely to be present for NMIBC determinants, rather than overall prognostic outcomes.

\section{Conclusions}

Our study suggests that variations in 13q13.3 locus may contribute to an increased NMIBC tumour size in a European population. Further studies are warranted to confirm the association.

Author contributions: Nadezda Lipunova had full access to all the data in the study and takes responsibility for the integrity of the data and the accuracy of the data analysis.

Study concept and design: Lipunova, Zeegers, Bryan, Wesselius. Acquisition of data: Lipunova, Galesloot, Bryan, Zeegers.

Analysis and interpretation of data: Lipunova, Wesselius, Cazier, Bryan, Zeegers, Galesloot.

Drafting of the manuscript: Lipunova.

Critical revision of the manuscript for important intellectual content: Wesselius, Bryan, Cazier, Zeegers, van Schooten, Cheng, Galesloot, Kiemeney.

Statistical analysis: Lipunova, Wesselius, Cazier, Bryan, Galesloot.

Obtaining funding: Cheng, Zeegers, Bryan.

Administrative, technical, or material support: Wesselius, Bryan, Zeegers, Galesloot, Kiemeney.

Supervision: Wesselius, Zeegers, Bryan, Cazier, van Schooten, Cheng. Other: None.
Financial disclosures: Nadezda Lipunova certifies that all conflicts of interest, including specific financial interests and relationships and affiliations relevant to the subject matter or materials discussed in the manuscript (eg, employment/affiliation, grants or funding, consultancies, honoraria, stock ownership or options, expert testimony, royalties, or patents filed, received, or pending), are the following: None.

Funding/Support and role of the sponsor: None.

\section{Appendix A. Supplementary data}

Supplementary data associated with this article can be found, in the online version, at doi:10.1016/j.euo.2018.08. 020 .

\section{References}

[1] Kamat AM, Hahn NM, Efstathiou JA, et al. Bladder cancer. Lancet 2016;388:2796-810.

[2] Sylvester RJ. How well can you actually predict which non-muscleinvasive bladder cancer patients will progress? Eur Urol 2011;60:431-3, discussion 433-4.

[3] Grotenhuis AJ, Dudek AM, Verhaegh GW, et al. Independent replication of published germline polymorphisms associated with urinary bladder cancer prognosis and treatment response. Bladder Cancer 2016;2:77-89.

[4] Chen M, Hildebrandt MA, Clague J, et al. Genetic variations in the sonic hedgehog pathway affect clinical outcomes in non-muscleinvasive bladder cancer. Cancer Prev Res 2010;3:1235-45.

[5] Ke HL, Chen M, Ye Y, et al. Genetic variations in micro-RNA biogenesis genes and clinical outcomes in non-muscle-invasive bladder cancer. Carcinogenesis 2013;34:1006-11.

[6] Galesloot TE, Grotenhuis AJ, Fleshner NE, et al. The role of germline genetic variants in the prognosis of non-muscle invasive bladder cancer: a meta-GWAS. Urol Oncol Semin Original Invest 2017;35:614.

[7] Lopez de Maturana E, Picornell A, Masson-Lecomte A, et al. Prediction of non-muscle invasive bladder cancer outcomes assessed by innovative multimarker prognostic models. BMC Cancer 2016;16:351.

[8] Marchini J, Howie B. Genotype imputation for genome-wide association studies. Nat Rev Genet 2010;11:499-511.

[9] Kitchen MO, Bryan RT, Emes RD, et al. Quantitative genome-wide methylation analysis of high-grade non-muscle invasive bladder cancer. Epigenetics 2016;11:237-46.

[10] Figueroa JD, Middlebrooks CD, Banday AR, et al. Identification of a novel susceptibility locus at 13q34 and refinement of the 20p12.2 region as a multi-signal locus associated with bladder cancer risk in individuals of European ancestry. Hum Mol Genet 2016;25:1203-14.

[11] Zeegers MP, Bryan RT, Langford C, et al. The West Midlands Bladder Cancer Prognosis Programme: rationale and design. BJU Int 2010;105:784-8.

[12] Purcell S, Neale B, Todd-Brown K, et al. Plink: a tool set for wholegenome association and population-based linkage analyses. Am J Hum Genet 2007;81:559-75.

[13] Loh PR, Danecek P, Palamara PF, et al. Reference-based phasing using the Haplotype Reference Consortium Panel. Nat Genet 2016;48:1443-8.

[14] Howie BN, Donnelly P, Marchini J. A flexible and accurate genotype imputation method for the next generation of genome-wide association studies. PLoS Genet 2009;5:e1000529.

[15] Clarke L, Fairley S, Zheng-Bradley X, et al. The International Genome Sample Resource (IGSR): a worldwide collection of genome variation 
incorporating the 1000 Genomes Project data. Nucleic Acids Res 2017;45:D854-9.

[16] R Foundation for Statistical Computing. R: a language and environment for statistical computing. Vienna, Austria: R Core Team; 2016, https://www.r-project.org

[17] Babjuk M, Bohle A, Burger M, et al. EAU guidelines on non-muscleinvasive urothelial carcinoma of the bladder: update 2016. Eur Urol 2017;71:447-61.

[18] Johnson JL, Abecasis GR. GAS power calculator: web-based power calculator for genetic association studies. bioRxiv. In press. https:// doi.org/10.1101/164343.

[19] Pruim RJ, Welch RP, Sanna S, et al. LocusZoom: regional visualization of genome-wide association scan results. Bioinformatics 2010;26:2336-7.

[20] Dayem Ullah AZ, Lemoine NR, Chelala C. SNPnexus: a web server for functional annotation of novel and publicly known genetic variants (2012 update). Nucleic Acids Res 2012;40:W65-70.

[21] Aken BL, Ayling S, Barrell D, et al. The Ensembl gene annotation system. Database. In press. https://doi.org/10.1093/database/baw093.
[22] Kiemeney LA, Thorlacius S, Sulem P, et al. Sequence variant on 8q24 confers susceptibility to urinary bladder cancer. Nat Genet 2008;40:1307-12.

[23] Liu JZ, Tozzi F, Waterworth DM, et al. Meta-analysis and imputation refines the association of $15 \mathrm{q} 25$ with smoking quantity. Nat Genet 2010;42:436-40.

[24] Niesmann K, Breuer D, Brockhaus J, et al. Dendritic spine formation and synaptic function require neurobeachin. Nat Commun 2011;2:557.

[25] Petrosyan A. Onco-Golgi: is fragmentation a gate to cancer progression? Biochem Mol Biol J 2015;1.

[26] Li X, Wu WK, Xing R, et al. Distinct subtypes of gastric cancer defined by molecular characterization include novel mutational signatures with prognostic capability. Cancer Res 2016;76:172432.

[27] Gao G, Kasperbauer JL, Tombers NM, Cornell MD, Smith DI. Prognostic significance of decreased expression of six large common fragile site genes in oropharyngeal squamous cell carcinomas. Transl Oncol 2014;7:726-31. 